\title{
Effect of Solar Radiation on Current-Carrying Capacity of PVC-insulated Power Cables - the Numerical Point of View
}

\author{
Stanislaw CZAPP, Seweryn SZULTKA, Adam TOMASZEWSKI, Agata SZULTKA
}

\begin{abstract}
Power cables are usually buried in the soil, which results in their relatively high current-carrying capacity. However, there are cases in which the starting/fina section of a cable line runs along a pole of an overhead power line. Power cables can be directly exposed to solar radiation then, and this negatively influences their currentcarrying capacity as well as estimated life of the cables' insulation. An analysis of thermal phenomena in PVC-insulated low-voltage power cables, exposed to solar radiation, is conducted in the paper. Current-carrying capacity of an example cable system, for various placements of the cables, is evaluated. The analysis has shown that solar radiation may significantly reduce current-carrying capacity of PVC-insulated cables. A possible method of protection of cables against solar radiation, and its effectiveness, is presented. To investigate the mentioned thermal phenomena, a Computational Fluid Dynamics (CFD) has been used.
\end{abstract}

Keywords: finite volume method; fluid flow; numerical simulation; power system analysis computing; thermal analysis

\section{INTRODUCTION}

Current-carrying capacity $I_{z}$ of power cables depends on many factors [1-5], especially on:

- cross-section and material of power cables conductor,

- $\quad$ soil thermal resistivity (for buried cables),

- transposition of cables,

- number of neighbouring electrical circuits,

- proximity to sources of heat (e.g. heating pipes),

- intensity of solar radiation (for cables installed in free air).

According to the standards [6,7] current-carrying capacity $I_{z}$ of power cables in AC power systems, exposed to solar radiation, can be calculated as follows:

$$
I_{\mathrm{z}}=\sqrt{\frac{\Delta \theta_{\mathrm{t}}-W_{\mathrm{d}}\left[0.5 T_{1}+n\left(T_{2}+T_{3}+T_{4}^{*}\right)\right]-\sigma d_{\mathrm{e}} H_{\mathrm{s}} T_{4}^{*}}{R T_{1}+n R\left(1+\lambda_{1}\right) T_{2}+n R\left(1+\lambda_{1}+\lambda_{2}\right)\left(T_{3}+T_{4}^{*}\right)}}
$$

where:

$d_{\mathrm{e}}-$ external diameter of cable,

$H_{\mathrm{s}}-$ intensity of solar radiation (usually $10^{3} \mathrm{~W} / \mathrm{m}^{2}$, but it is recommended to assume a local value),

$n$ - number of conductors in a cable,

$R$ - AC current resistance of a conductor at its maximum operating temperature,

$T_{1}$ - thermal resistance per core between the conductor and sheath,

$T_{2}$ - thermal resistance between the sheath and armour,

$T_{3}$ - thermal resistance of external serving of the cable,

$T_{4}{ }^{*}$ - external thermal resistance in free air, adjusted for solar radiation,

$W_{\mathrm{d}}-$ dielectric losses per unit length per phase,

$\lambda_{1}$ - ratio of the total losses in metallic sheaths to the total conductor losses,

$\lambda_{2}-$ ratio of the total losses in metallic armour to the total conductor losses,

$\Delta \Theta_{\mathrm{t}}-$ permissible temperature rise of the conductor above ambient temperature,

$\sigma$ - absorption coefficient of solar radiation for the cable surface.
An accurate calculation of the current-carrying capacity, based on (1), requires the assumption of many coefficients values, and in some cases, their evaluation with the use of iterative methods. As an alternative and more precise calculation of current-carrying capacity of power cables exposed to solar radiation, a method using modelling of thermal phenomena in cables, based on Computational Fluid Dynamics (CFD), can be used [8, 9]. Modelling studies have been conducted with the use of the ANSYS Fluent software. The advantage of such calculations is the possibility of modelling various complicated/adverse conditions of cables installation [10], and mixed external influences, especially effect of solar radiation and wind, what is developed in this paper.

Adverse ambient conditions/layout of power cables placed in the air, affecting the limitation of their load, can be reduced by a suitable cooling system. A passive cooling system of power cables is the most suitable for use in power installations due to its advantages. The undoubted advantages of this cooling system include no energy consumption for work and reliability. However, the efficiency of this cooling system depends on the amount of air flowing around the power cables. The use of a passive cooling system is considered in [11-14] as well as analyzed in this paper.

In the paper, a low-voltage power cable system with PVC-insulated cables is considered. Current-carrying capacity of the cables, installed in the soil and partly exposed to solar radiation is analyzed. Efficiency of cables protection against solar radiation, by application of plastic pipes, is discussed.

\section{ANALYZED MODEL OF THE POWER CABLE SYSTEM}

To evaluate the impact of solar radiation on power cables, a section of low-voltage 3-phase cable system is considered (Fig. 1). The above mentioned power cable system consists of three single-core PVC-insulated power cables (nominal cross-sectional area of the copper conductor: $35 \mathrm{~mm}^{2}$ ). Flat formation with distance between cables equal to one external diameter is assumed. The diameter of the copper conductor is $d_{\mathrm{w}}=7,2 \mathrm{~mm}$ and the 
external diameter with the PVC insulation is $d_{\mathrm{e}}=12,4 \mathrm{~mm}$. The ambient reference temperature of air is $t_{\text {air }}=25^{\circ} \mathrm{C}$.

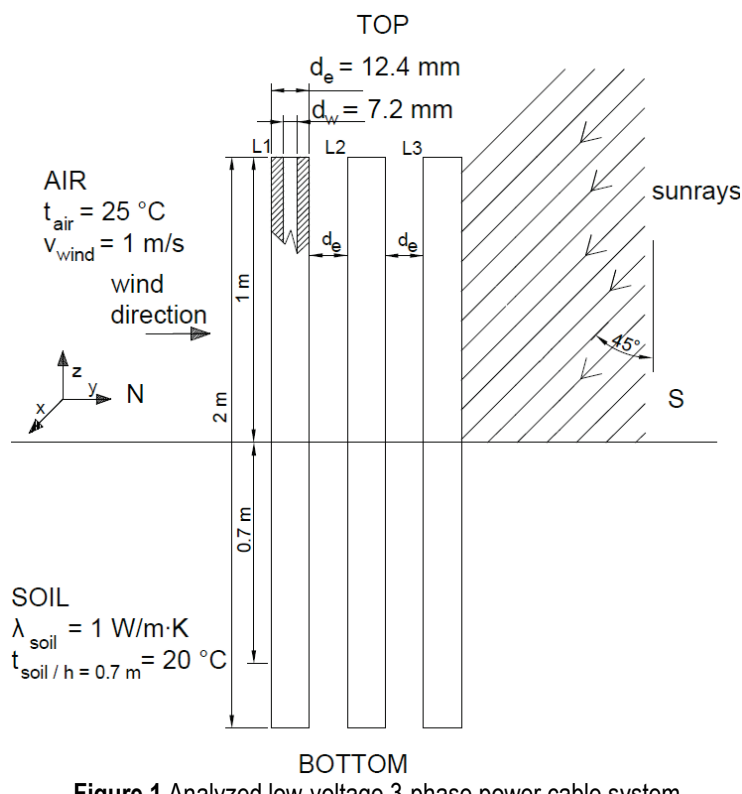

Figure 1 Analyzed low-voltage 3-phase power cable system

The wind direction is North to South and wind speed equal to $v_{\text {wind }}=1 \mathrm{~m} / \mathrm{s}$ is assumed. The thermal conductivity of soil is equal to $\lambda_{\text {soil }}=1 \mathrm{~W} /(\mathrm{m} \cdot \mathrm{K})$. The soil temperature at a depth of $0,7 \mathrm{~m}$ is $20^{\circ} \mathrm{C}$. Solar radiation corresponds to the average solar exposure conditions in Central Europe. The sun's altitude is $45^{\circ}$. The numerical model refers to the conditions that occur during the summer in the Polish geographical conditions. Simulations were carried out in 3D (xyz) domain, but Fig. 1 presents a simplified 2D description, as well as an indication of the boundary conditions.

\section{THE ENERGY BALANCE OF THE POWER CABLE SYSTEM}

In the presented model, the heat generated in the system and transferred to the environment is considered. Generation of heat in the system is carried out by:

- Joule's heat which is described by heat flux density $q_{\mathrm{J}}, \mathrm{W} / \mathrm{m}^{2}$. For cases of electric current flow, the value of $q_{\mathrm{J}}$ is increased until the temperature of cable insulation in any place reaches the upper limit value $t_{\max }=70{ }^{\circ} \mathrm{C}$. The current-carrying capacity $I_{z}$ is calculated from this maximum value of $q_{\mathrm{J}}$ available in the system, after rearranging the following Eq. (2):

$q_{\mathrm{J}}=\frac{Q_{\mathrm{J}}}{A_{1 \mathrm{~m}}}=\frac{I_{\mathrm{z}}^{2} R_{\mathrm{lm}}}{\pi d_{\mathrm{w}}}$

where:

$Q_{\text {J }}$ - thermal power generated per $1 \mathrm{~m}$ power cable length, $\mathrm{W}$,

$A_{1 \mathrm{~m}}-$ area of the copper conductor of $1 \mathrm{~m}$ power cable length, $\mathrm{m}^{2}$,

$R_{1 \mathrm{~m}}$ - electrical resistance of $1 \mathrm{~m}$ power cable length, $\Omega$,

$I_{\mathrm{z}}$ - current-carrying capacity, A.
- Solar irradiation heat - heat flux density from solar radiation $q_{\mathrm{S}}(x), \mathrm{W} / \mathrm{m}^{2}$ is a function defined by the authors. The relationship shows the dependence between heat flux density from solar irradiation delivered to surface of cable insulation $q_{\mathrm{s}}(x), \mathrm{W} / \mathrm{m}^{2}$, and the $x$ location. The heat from solar irradiation is introduced to the right side of the right cable (see Fig. 1). The obtained correlation is a result of a variable incidence angle of sunrays on the surface area of the insulation. Solar irradiation is calculated for the sun's altitude of $45^{\circ}$. In order to get the proper value of the heat flux density delivered to the surface of the insulation, perpendicular to solar rays, the Westman's equation [15] is multiplied by the PVC absorbance factor of $\sigma=0,9$ which describes Eq. (3):

$q_{1}=\sigma H_{\mathrm{s}} \times 10^{-0,05675 k+0,00038 k^{2}}$

where: $H_{\mathrm{s}}=$ const $=1120 \mathrm{~W} / \mathrm{m}^{2} ; k=1 / \sin A_{\mathrm{L}} ; A_{\mathrm{L}} \approx 45^{\circ}-$ the sun's altitude.

Further equations are obtained from geometrical dependencies. Heat flux density delivered to a vertical surface [15] describes Eq. (4):

$q_{\mathrm{V}}=q_{1} \cdot \cos \left(A_{\mathrm{L}}\right)$

When the vertical surface normal is tilted with an azimuth angle from the sun's azimuth, the relationship is as follows [15]:

$q_{\mathrm{S}}\left(A z_{\mathrm{SURFACE}}\right)=q_{1} \cdot \cos \left(A_{\mathrm{L}}\right) \cdot \cos \left(A z_{\mathrm{SUN}}-A z_{\mathrm{SURFACE}}\right)$

where: $A z_{\text {SURFACE }}-$ azimuth of the surface normal, $A z_{\mathrm{SUN}^{-}}-$ sun's azimuth.

The Eq. (5) is valid for the following angle range (6):

$\left|A z_{\text {SUN }}-A z_{\text {SURFACE }}\right| \leq 90^{\circ}$

The Eq. (3) is converted to the relationship (7):

$q_{\mathrm{S}}(x)=\sigma \cdot \cos \left(A_{\mathrm{L}}\right) \cdot \frac{x}{r_{\mathrm{e}}} \cdot H_{\mathrm{S}} \times 10^{-0,05675 k+0,00038 k^{2}}$

where:

$r_{\mathrm{e}}$ - external radius of the insulation, $\mathrm{mm}$, $x$ - coordinate.

In the analyzed cases, the power cable gives back heat to the environment by:

- Convection - the natural convection is analyzed. The heat flux $q_{\text {conv }}, \mathrm{W} / \mathrm{m}^{2}$, that is transferred by convection, can be obtained from Eq. (8):

$q_{\mathrm{conv}}=\alpha\left(t_{\mathrm{s}}-t_{\mathrm{air}}\right)$

This type of heat exchange depends on the temperature of the heat exchange surface $t_{\mathrm{s}}$ and the ambient temperature $t_{\text {air. }}$ Additionally, the heat flux depends on the heat transfer coefficient $\alpha, \mathrm{W} /\left(\mathrm{m}^{2} \cdot \mathrm{K}\right)$. The $\alpha$ coefficient depends on the air velocity flowing around the surface of the cable, the direction of the components of the air vectors in relation to 
the surface of the cable. Convection is a key mechanism for heat exchange for a cable installed in the air.

- Conduction - the dominant mechanism of heat exchange for a part of the power system installed in the ground. Assuming the isotropy of the model, the heat flux density $q_{\text {cond }}, \mathrm{W} / \mathrm{m}^{2}$, transmitted by conduction, describes the relationship (9):

$q_{\text {cond }}=-\lambda_{\text {soil }} \nabla t$

where:

$\lambda_{\text {soil }}$ - thermal conductivity of the material (soil), $\mathrm{W} /(\mathrm{m} \cdot \mathrm{K})$,

$\nabla t$ - three-dimensional temperature gradient, $\mathrm{K} / \mathrm{m}$.

The model includes conduction in solids.

- Radiation - it is assumed that the surface of the cable has an emissivity $\varepsilon \approx 0,9$. The amount of heat transferred by radiation is based on the Discrete Ordinates (DO) radiation model [16]. The radiation is taken into account in further calculations, where there is a single cable located in a pipe or in free air. There is no need to include radiation effects in cases when nearby there are two or more sources of radiation, with similar temperature. In such cases, first medium emits, approximately, the same amount of radiation, what is absorbed from the radiation emitted by the second medium. In consequence, the maximum temperature of three cables located nearby is almost the same, regardless of whether the effect of radiation is taken or not taken into account. In order to check this, a single calculation for three cables was performed. The maximal temperature of cables differed only by $1{ }^{\circ} \mathrm{C}$ in such cases, when radiation is taken into account and when radiation is not taken into account.

\section{RESULTS OF NUMERICAL SIMULATIONS OF CURRENT-CARRYING CAPACITY OF POWER CABLES}

The results of the first simulation show the temperature distribution in the power cable system in case of maximal symmetric load of the cables without taking into account the solar radiation (Fig. 2). The value of current in each cable is equal to $179,2 \mathrm{~A}$, and gives the insulation maximal temperature $70^{\circ} \mathrm{C}$. In contrast, the cable insulation in the ground reaches only $63{ }^{\circ} \mathrm{C}$. The cable in phase $\mathrm{L} 1$ (on the left side of the picture in Fig. 2) has the lowest temperature, due to direct exposition to the wind $(1 \mathrm{~m} / \mathrm{s})$.

Fig. 3 shows the temperature distribution for power cables loaded symmetrically, including solar radiation. It can be seen that the most unfavourable temperature distribution is on the surface of the cable on the right side of the picture (phase L3) - this cable is directly exposed to the solar radiation. The maximum permissible temperature of the cable's insulation $\left(70^{\circ} \mathrm{C}\right)$ is reached, when the current value in each conductor is equal to $122,3 \mathrm{~A}$.

Other two cables (in phases L1 and L2) could be loaded more. Additionally, in such a system, the maximum temperature of the PVC insulation in the ground is only $37{ }^{\circ} \mathrm{C}$ (for current $122,3 \mathrm{~A}$ ). Based on the simulations, it can be concluded that for the installation of power cables in configuration "ground - air", a much worse heat exchange condition occurs in the air.

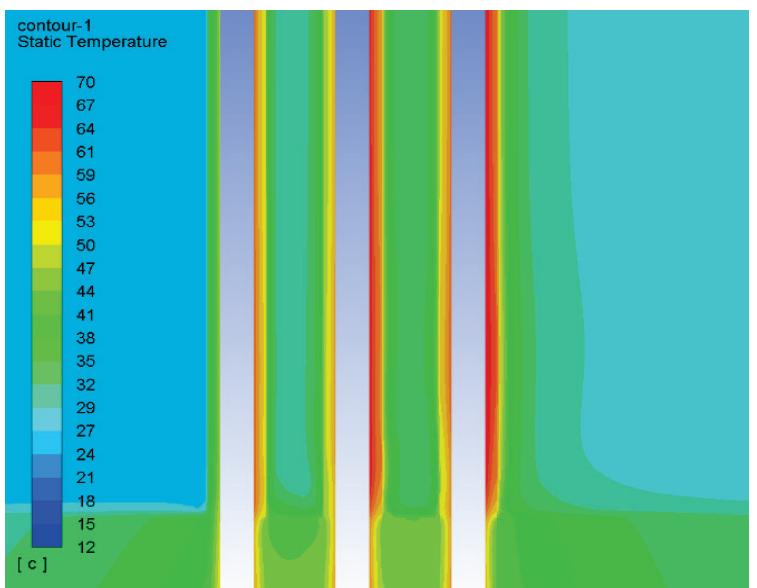

Figure 2 Temperature distribution around the surface of power cables (magnified) - without solar radiation, wind from left to right $v_{\text {wind }}=1 \mathrm{~m} / \mathrm{s}$, $\max$ symmetric load: $I_{\mathrm{zL} 1}=I_{\mathrm{zL} 2}=I_{\mathrm{zL} 3}=179,2$ A

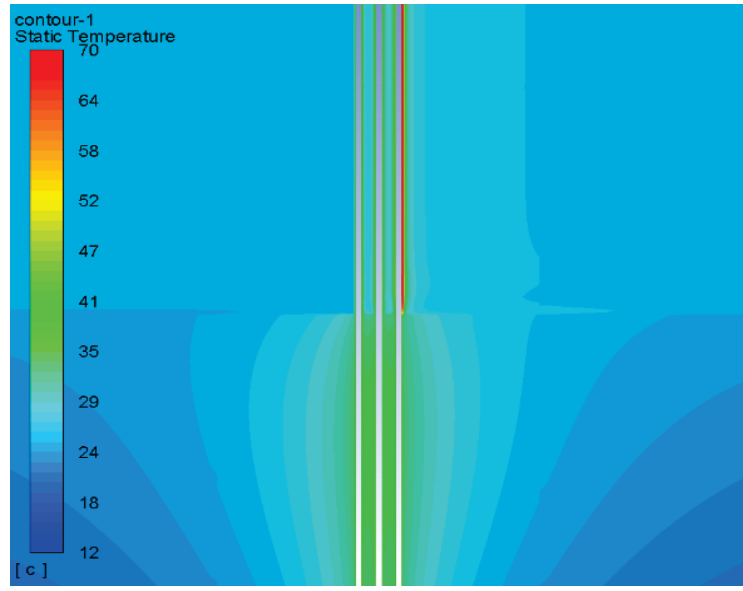

Figure 3 Temperature distribution around the surface of power cables - with solar radiation, wind from left to right $v_{\text {wind }}=1 \mathrm{~m} / \mathrm{s}$, symmetric load: $I_{\mathrm{zL} 1}=I_{\mathrm{zL} 2}=I_{\mathrm{zL} 3}=122,3 \mathrm{~A}$

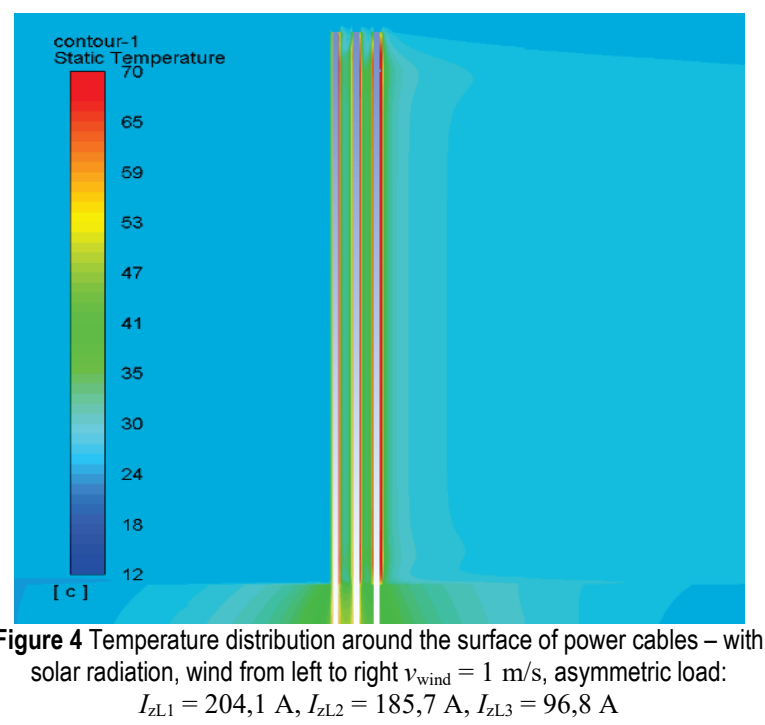

In order to achieve upper limit of insulation temperature in each cable $\left(70^{\circ} \mathrm{C}\right)$, including effect of solar radiation, the following values of current have been forced in cables conductors:

- $\quad$ phase L1: $I_{\mathrm{zL} 1}=204,1 \mathrm{~A}$

- $\quad$ phase L2: $I_{\mathrm{zL} 2}=185,7 \mathrm{~A}$

- $\quad$ phase L3: $I_{\mathrm{zL} 3}=96,8 \mathrm{~A}$. 
The temperature distribution around the surface of power cables is presented in Fig. 4.

Significant difference in the permissible load of individual phases strictly depends on the ambient conditions. The power cable L1 has the highest currentcarrying capacity - this cable is shielded from the direct influence of solar radiation and has an unlimited inflow of air with velocity $v_{\text {wind }}=1 \mathrm{~m} / \mathrm{s}$, directed perpendicular to the power cable axis. The power cable L2 has slightly worse heat transfer conditions (lower load value than in the case of the L1 power cable) - this results in an additional effect of heating insulation due to thermal influence of adjacent power cables and reduced airflow due to L1 power cable. In the case of the L3 power cable, solar radiation is the most dominant - current-carrying capacity of this conductor is around twice smaller than that of the conductors L1 and L2.

The next part of the paper presents a detailed analysis of thermal condition in a simplified, one cable system, and effects of application of a vertical pipe for a cable shielding against mechanical damage as well as exposure to direct solar radiation.

\section{ANALYSIS OF THE LIMITATION OF ADVERSE EFFECTS OF SOLAR RADIATION ON CURRENT- CARRYING CAPACITY OF POWER CABLES}

In order to decrease the time of calculation, further simulations are carried out on the simplified model, which consists of one single-core low-voltage power cable installed in the air. In contrast to the simulations made for a three-phase system, the air velocity is significantly reduced - its value is equal to $v_{\text {wind }}=0,01 \mathrm{~m} / \mathrm{s}$ (almost air stagnation, air flow is modelled in the bottom - top direction), which corresponds to the boundary condition of the air flow rate $m=0,0001 \mathrm{~kg} / \mathrm{s}$. The reason for these changes is an attempt to conduct a more precise analysis of the impact of natural convection and get better convergence in calculations, as well as to reflect the worst possible ambient condition for the cable. As a result, heat exchange conditions correspond to natural convection which is typical for power cables installed in free air. The angle of incidence of sunlight has been increased from 45 to 60 degrees. Moreover, the DO radiation model has been implemented to calculations. It has been used in calculations for a single cable surrounded by free air and for a single cable located in a pipe.

Fig. 5 shows the sun irradiation impact on the power cable insulation. The cable insulation reaches maximal permissible temperature $\left(70^{\circ} \mathrm{C}\right)$ for load $126 \mathrm{~A}$. The air velocity distribution for this case is depicted in Fig. 6. When solar radiation is not taken into account, the power cable can be loaded with current equal to $162 \mathrm{~A}$, and insulation maximum permissible temperature $\left(70{ }^{\circ} \mathrm{C}\right)$ is not exceeded, as shown in Fig. 7.

To limit the effect of solar radiation on currentcarrying capacity, the plastic pipe is modelled, in which the power cable is installed coaxially. Simulations were carried out in domain in which the diameter of the plastic pipe was variable. The pipe characterized by an outer diameter of $D=25 \div 500 \mathrm{~mm}$ and wall thickness of $\delta=5 \mathrm{~mm}$ is made of PVC. The absorbance coefficient of the pipe surface is $\sigma=0,9$ and the thermal conductivity of the $\mathrm{PVC}$ is $\lambda_{\mathrm{PVC}}=0,16 \mathrm{~W} /(\mathrm{m} \cdot \mathrm{K})$.
The example temperature distribution for a system with the PVC pipe $(D=200 \mathrm{~mm})$ and solar radiation is presented in Fig. 8. The simulations show that the cable in such a system can be loaded with the current value of $146,7 \mathrm{~A}$. The maximum insulation temperature in this system is $70^{\circ} \mathrm{C}$.

What is important, in spite of the use of a pipe, which usually reduces permissible load of the cables (even strong if not properly selected), in this case the current-carrying capacity is significantly better $(146,7 \mathrm{~A})$ than without a pipe (126 A - Fig. 5).

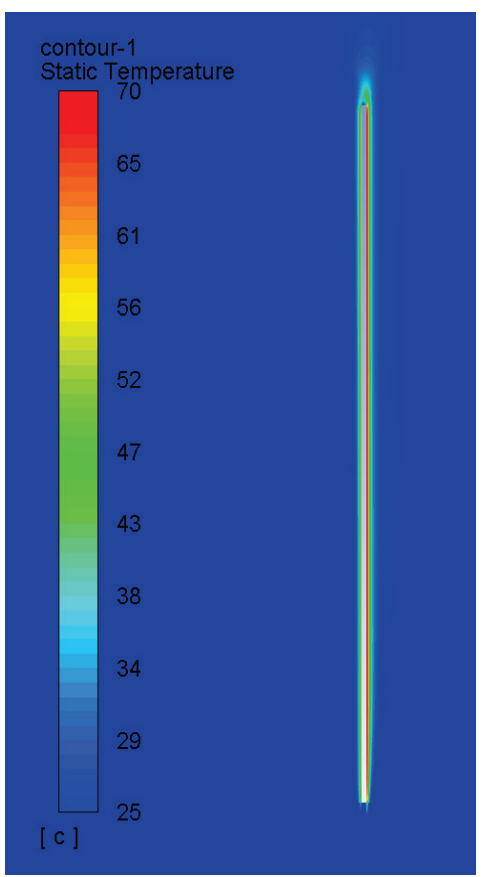

Figure 5 Temperature distribution around a single power cable - with solar radiation, wind from bottom to top $v_{\text {wind }}=0,01 \mathrm{~m} / \mathrm{s}$, load: $I_{\mathrm{z}}=126 \mathrm{~A}$

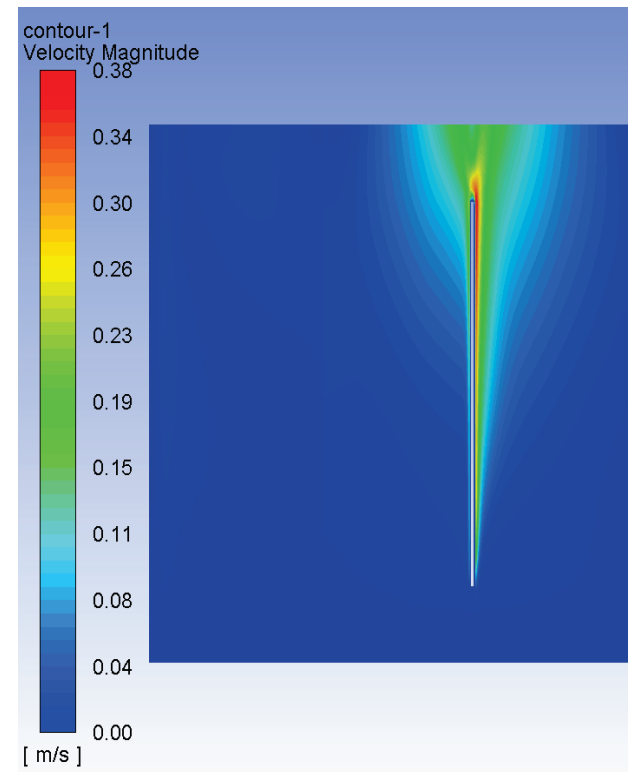

Figure 6 Air velocity distribution around a single power cable - with solar radiation, wind from bottom to top $v_{\text {wind }}=0,01 \mathrm{~m} / \mathrm{s}$, load: $I_{\mathrm{z}}=126 \mathrm{~A}$

Fig. 9 shows the air velocity distribution around the power cable in the pipe (with solar radiation). It indicates that the hot air at the top of the pipe reaches the maximum value of $v=0,44 \mathrm{~m} / \mathrm{s}$, whereas for the case with solar radiation and no pipe (Fig. 6) it reaches only $v=0,38 \mathrm{~m} / \mathrm{s}$. 


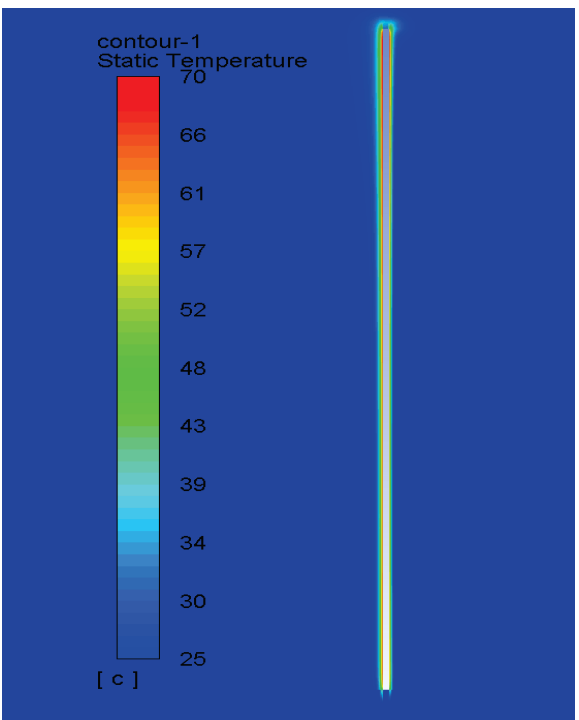

Figure 7 Temperature distribution around a single power cable - without solar radiation, wind from bottom to top $v_{\text {wind }}=0,01 \mathrm{~m} / \mathrm{s}$, load $I_{\mathrm{z}}=162 \mathrm{~A}$

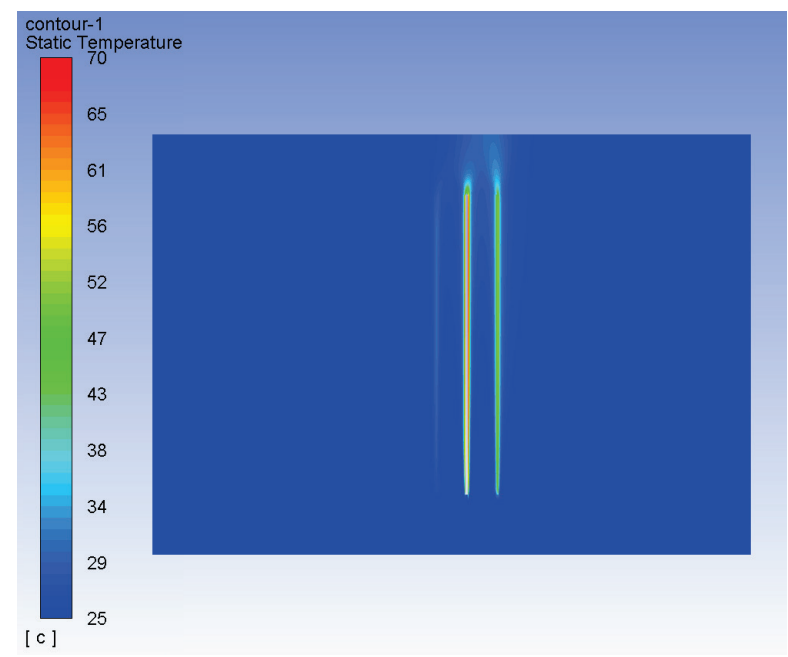

Figure 8 Temperature distribution around a power cable in a plastic pipe - with solar radiation, wind from bottom to top $v_{\text {wind }}=0,01 \mathrm{~m} / \mathrm{s}$, load $I_{\mathrm{z}}=146,7$ A

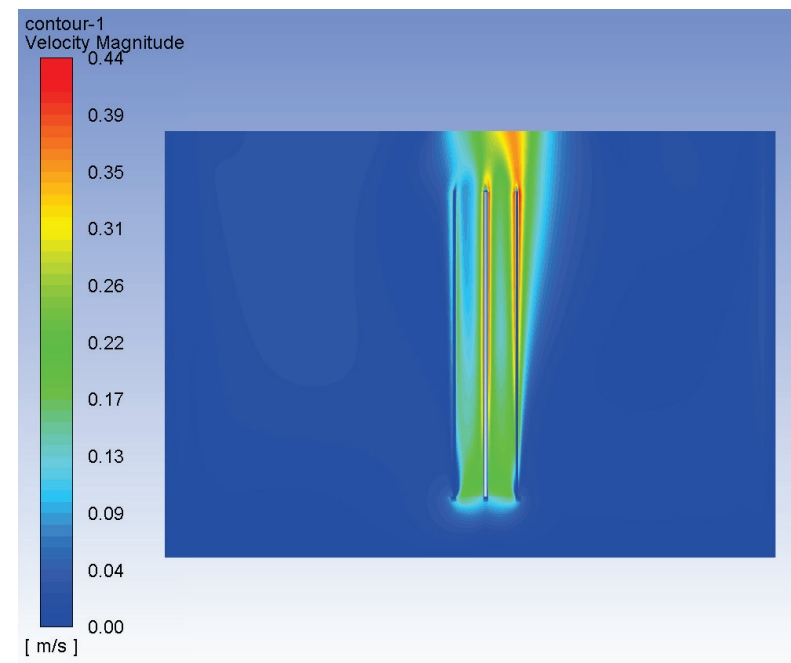

Figure 9 Air velocity distribution around a power cable in a plastic pipe - with solar radiation, wind from bottom to top $v_{\text {wind }}=0,01 \mathrm{~m} / \mathrm{s}$, load $I_{\mathrm{z}}=146,7 \mathrm{~A}$

The PVC pipe not only blocks solar radiation. If the power cable is placed in it, which enables air inflow at its lower part, and solar radiation occurs, the more intensive chimney effect is achieved. As a result, the share of heat energy delivered by convection increases (increase in the $\alpha$ coefficient) $[17,18]$. The proposal to place the cable in the pipe is a kind of passive cooling system.

The efficiency of the passive cooling system increases significantly with the use of the chimney effect. The greater the thermal difference and the height of the structure, the greater the buoyancy force, and thus the chimney effect.

The chimney effect enhances natural ventilation and air infiltration. Research on the chimney effect was carried out by researchers at various levels [19-21]. Taking the above into account, when solar radiation occurs, power cables in pipes can be loaded higher, as shown in the results of extensive simulations included in Fig. 10.

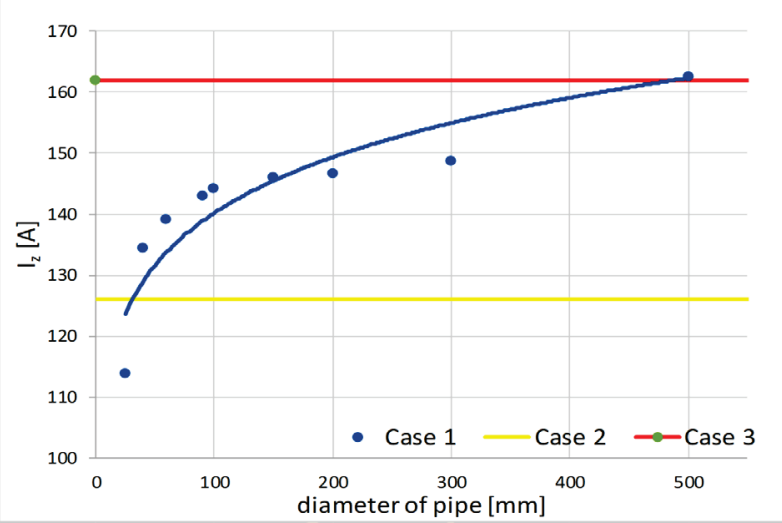

Figure 10 Current-carrying capacity of a power cable as a function of the pipe diameter, and comparison with the reference cases. Case 1: The cable placed in variable diameter pipe - passive cooling system, Case 2: The cable without pipe, with solar radiation - see Fig. 5. Case 3: The cable without pipe, without solar radiation - see Fig. 7

On the basis of Fig. 10, it can be seen that the use of passive cooling system significantly improves the currentcarrying capacity of the cable (case 1) compared to the cable without the pipe and under solar radiation (case 2). In fact, the adverse effect of solar radiation on the heating of the power cable is limited. However, "cable - pipe" dimensions have to be optimized. As it can be seen at the left side of Fig. 10, very narrow pipe is too small to achieve an improved current-carrying capacity compared to case 2 - for a pipe with $25 \mathrm{~mm}$ outer diameter, current-carrying capacity $I_{z}$ is lower (case 1) than for a cable without a pipe (case 2). If the pipe diameter is too small, there is greater air viscous resistance in the duct between the pipe and the cable. In this way, the beneficial impact of the chimney effect is significantly reduced.

\section{CONCLUSION}

The above presented results of numerical simulations show that the likelihood of overheating the insulation of power cables is higher when cables are installed in free air than in the ground. It is clearly visible that the impact of solar radiation on current-carrying capacity of power cables is significant, during summer in Central Europe. The impact of solar radiation can reduce the load of power cables by almost $1 / 3$ as compared to the lack of sunlight (179,2 A vs. 122,3 A - current-carrying capacity of the power cables is reduced by $32 \%$ ).

In order to verify protection of cables against the negative effect of solar radiation, placing a single power cable in a pipe has been examined. The pipe cuts off the solar radiation but also reduces some amount of heat (negative effect) which is transferred to air by convection. 
Wrong dimension of the pipe (too small diameter) may lead to deterioration of heat exchange conditions and mass around the power cable and thus additionally reduce the value of current-carrying capacity below the reference values. However, proper relation of dimensions "cable pipe" may give a positive chimney effect, resulting in the improved current-carrying capacity. By using a properly selected pipe, the current-carrying capacity of the analyzed cable can be increased even around $30 \%$ in relation to the case without a pipe.

Such pipes can be very useful in case of strong solar radiation. Further research will concern the selection/optimization of dimensions "cable - pipe" (intensification of the chimney effect) in various configurations to improve the current-carrying capacity of power cables in vertical pipes.

\section{REFERENCES}

[1] Sedaghat, A. \& De Leon, F. (2014). Thermal Analysis of Power Cables in Free Air: Evaluation and Improvement of the IEC Standard Ampacity Calculations. IEEE Transactions on Power Delivery, 29(5), 2306-2314. https://doi.org/10.1109/TPWRD.2013.2296912

[2] De León, F. (2006). Major factors affecting cable ampacity. 2006 IEEE Power Engineering Society General Meeting. https://doi.org/10.1109/PES.2006.1708875

[3] Czapp, S., Szultka, S., \& Tomaszewski, A. (2017). CFDbased evaluation of current-carrying capacity of power cables installed in free air. 2017 18th International Scientific Conference on Electric Power Engineering (EPE). https://doi.org/10.1109/EPE.2017.7967271

[4] Low-voltage electrical installations - Part 5-52: Selection and erection of electrical equipment - Wiring systems, IEC 60364-5-52, 2009.

[5] Klimenta, D., Perović, B., Klimenta, J., Jevtić, M., Milovanović, M., \& Krstić, I. (2018). Modelling the thermal effect of solar radiation on the ampacity of a low voltage underground cable. International Journal of Thermal Sciences, 134, 507-516. https://doi.org/10.1016/J.IJTHERMALSCI.2018.08.012

[6] Electric cables - Calculation of the current rating - Part 1-1: Current rating equations (100\% load factor) and calculation of losses - General, IEC 60287-1-1, 2006.

[7] Electric Cables - Calculation of the Current Rating - Part 2: Thermal Resistance - Calculation of the thermal resistance, IEC 60287-2-1, 2001.

[8] Holyk, C. \& Anders, G. (2015). Power Cable Rating Calculations - A Historical Perspective [History]. IEEE Industry Applications Magazine, 21(4), 6-64. https://doi.org/10.1109/MIAS.2015.2417094

[9] Plesca, A. \& Scintee, A. (2010). Thermal Aspects Related to Power Assemblies. Advances in Electrical and Computer Engineering, 10(1), 23-27. https://doi.org/10.4316/AECE.2010.01004

[10] Czapp, S., Czapp, M., Szultka, S., \& Tomaszewski, A. (2018). Ampacity of power cables exposed to solar radiation - recommendations of standards vs. CFD simulations. E3S Web of Conf., $17^{\text {th }}$ International Conference Heat Transfer and Renewable Sources of Energy (HTRSE-2018). https://doi.org/10.1051/e3sconf/20187003004

[11] Amr, A. A., Hassan, A., Abdel-Salam, M., \& El-Sayed, A. H. (2017). Enhancement of photovoltaic system performance via passive cooling. In Power Systems Conference (MEPCON), 2017 Nineteenth International Middle East Power Systems Conference (MEPCON). https://doi.org/10.1109/MEPCON.2017.8301371

[12] Bădălan, N. \& Svasta, P. (2017). Fan vs. passive heat sink with heat pipe in cooling of high power LED. 2017 IEEE 23rd International Symposium for Design and Technology in Electronic Packaging (SIITME). https://doi.org/10.1109/SIITME.2017.8259911

[13] Dupont, V., Billet, C., \& Nicolle, T. (2016). High Performances Passive Two-Phase Loops for Power Electronics Cooling. International Exhibition and Conference for Power Electronics, Intelligent Motion, Renewable Energy and Energy Management (PCIM Europe 2016). https://ieeexplore.ieee.org/stamp/stamp.jsp?tp= \&arnumber $=7499484$

[14] Liang, K., Li, Z., Chen, M., \& Jiang, H. (2019). Comparisons between heat pipe, thermoelectric system, and vapour compression refrigeration system for electronics cooling. Applied Thermal Engineering, 146, 260-267. https://doi.org/10.1016/J.APPLTHERMALENG.2018.09.120

[15] Andersen, S. A. \& Andersen, S. A. (1959). Automatic refrigeration. Published by MacLaren for Danfoss, Nordborg, Denmark.

[16] Mikaél', A. B. (2013). Infrared Radiation: A Handbook for Applications. Springer Science \& Business Media.

[17] Czapp, S. \& Czapp, M. (2013). Intensification of Thermal Convection Near Electric Devices using Flat ScreensComputer Modelling. Elektronika ir Elektrotechnika, 19(2). https://doi.org/10.5755/J01.EEE.19.2.3462

[18] Czapp, S., Czapp, M., \& Orlowska, M. (2016). Numerical and experimental investigation of thermal convection near electric devices with vertical channels. 2016 International Conference on Information and Digital Technologies (IDT). https://doi.org/10.1109/DT.2016.7557149

[19] Auletta, A., Manca, O., Morrone, B., \& Naso, V. (2001). Heat transfer enhancement by the chimney effect in a vertical isoflux channel. International Journal of Heat and Mass Transfer, 44(22), 4345-4357. https://doi.org/10.1016/S0017-9310(01)00064-3

[20] Straatman, A. G., Tarasuk, J. D., \& Floryan, J. M. (1993). Heat transfer enhancement from a vertical, isothermal channel generated by the chimney effect. Journal of Heat Transfer, 115(2), 395-402. https://doi.org/10.1115/1.2910691

[21] Kitamura, Y. \& Ishizuka, M. (2004). Study on chimney effect on natural air cooling of electronic equipment under inclination. The Ninth Intersociety Conference on Thermal and Thermomechanical Phenomena In Electronic Systems. https://doi.org/10.1109/ITHERM.2004.1319163

Contact information:

Stanislaw CZAPP, PhD, Eng., Associate Professor

(Corresponding author)

Faculty of Electrical and Control Engineering

Gdansk University of Technology,

Narutowicza 11/12, PL-80-233 Gdansk, Poland

E-mail: stanislaw.czapp@pg.edu.pl

Seweryn SZULTKA, PhD, Eng

Faculty of Electrical and Control Engineering,

Gdansk University of Technology,

Narutowicza 11/12, PL-80-233 Gdansk, Poland

E-mail: seweryn.szultka@pg.edu.pl

Adam TOMASZEWSKI, MSc, Eng., Specialist

Institute of Fluid-Flow Machinery,

Polish Academy of Sciences

Fiszera 14, PL-80-231 Gdansk, Poland

E-mail: atomaszewski@imp.gda.pl

Agata SZULTKA, MSc, Eng., PhD student Faculty of Electrical and Control Engineering, Gdansk University of Technology,

Narutowicza 11/12, PL-80-233 Gdansk, Poland

E-mail: agata.szultka@pg.edu.pl 